\title{
Association between EGFR mutation and expression of BRCA1 and RAP80 in non-small cell lung cancer
}

\author{
XIA SUN ${ }^{1 *}$, FANGBO CUI $^{2 *}$, HUAFANG YIN $^{1}$, DAN WU $^{1}$, NANYAO WANG $^{1}$, \\ MING YUAN $^{1}$, YANHUA FEI ${ }^{1}$ and QIONG WANG ${ }^{1}$ \\ ${ }^{1}$ Department of Oncology, The Affiliated Jiangyin Hospital of Southeast University Medical College, \\ Wuxi, Jiangsu 214400; ${ }^{2}$ Department of Oncology, The People's Hospital of Ma'Anshan, \\ Maanshan Shi, Anhui 243000, P.R. China
}

Received January 3, 2018; Accepted May 9, 2018

DOI: $10.3892 / \mathrm{ol} .2018 .8938$

\begin{abstract}
Association between the epithelial growth factor receptor (EGFR) mutation and the expression of breast cancer 1 (BRCA1) and receptor-associated protein 80 (RAP80) in non-small cell lung cancer (NSCLC) was studied. From September 2014 to September 2016, 51 patients with NSCLC who were hospitalized in Department of Thoracic Surgery in The Affiliated Jiangyin Hospital of Southeast University Medical College and underwent biopsy or operation were selected. The pathological changes of lung tissue were detected by hematoxylin and eosin histopathological staining. The fluorescent expression of BRCA1 and RAP80 protein in the two groups was determined by immunofluorescence staining. Reverse transcriptase polymerase chain reaction method and western blot analysis were used to detect BRCA1 and RAP80 mRNA and protein expression. Then the EGFR gene mutation was detected and analyzed. The results show that non-small cell lung cancer has an association with smoking. Compared with the control, the lung tissue structure of the NSCLC group was damaged. The protein fluorescence expression of BRCA1 and RAP80 in non-small cell lung cancer group was significantly increased. The expression of BRCA1 and RAP80 mRNA and protein in NSCLC group was significantly increased. The difference in expression of BRCA1 and RAP80 in the control and the non-small cell lung cancer group was statistically significant $(\mathrm{P}<0.05)$. EGFR gene mutations detected 14 of the 51 patients with
\end{abstract}

Correspondence to: Dr Qiong Wang, Department of Oncology, The Affiliated Jiangyin Hospital of Southeast University Medical College, 163 Shoushan Road, Wuxi, Jiangsu 214400, P.R. China

E-mail: sunplease09@163.com

"Contributed equally

Key words: non-small cell lung cancer, BRCA1, RAP80, EGFR mutation genetic mutations. Non-small cell lung cancer and smoking have certain relevance, and BRCA1 and RAP80 expression in the development and progression of NSCLC has a close relationship. EGFR mutation in non-small cell lung cancer significantly related to the mutation of EGFR and BRCA1 and RAP8O gene expression plays an important role in the diagnosis and treatment of NSCLC.

\section{Introduction}

The morbidity and mortality rates of lung cancer rank first in malignant tumors, among which non-small cell lung cancer (NSCLC) occupies a major position in lung cancer, so finding treatment for NSCLC is extremely urgent (1). At present, the treatment of NSCLC has been developed from traditional comprehensive treatment, such as surgery and chemotherapy, to individualized treatment. However, the cure rate is not high and NSCLC cannot be radically cured, so better treatment means and methods are still needed (2,3). A large number of studies have shown that the poor prognosis of patients with NSCLC may be related to a low response rate to chemotherapy or primary/secondary drug resistance produced during the process of combined chemotherapy (4). With the deepening of research on related genes to the prediction of curative effect of chemotherapeutic and targeted drugs, the development and application of individualized chemotherapy and individualized targeted therapy for NSCLC have been greatly promoted (5). Genes, such as epithelial growth factor receptor (EGFR), breast cancer 1 (BRCAl) and receptor-associated protein 80 (RAP80), are all effective genes in the treatment of NSCLC. The combined detection of several genes that can predict the curative effect can provide an important reference basis for the development of NSCLC treatment programs (6). In the present study, expression of BRCAI and RAP8O and EGFR gene mutations in 51 NSCLC patients were detected, and their association were analyzed, so as to understand the association of EGFR gene mutations with expression of BRCA1 and RAP80 in NSCLC patients, and provide a basis for further exploring more effective individualized treatment programs for NSCLC patients. 


\section{Materials and methods}

\section{Patients}

General data. In the present study, 51 NSCLC patients admitted and treated in the Thoracic Surgery Department of The Affiliated Jiangyin Hospital of Southeast University Medical College (WuXi, China) and who underwent biopsy or surgery from September 2014 to September 2016 were selected, and general data and smoking status were recorded. The study was approved by the Ethics Committee of The Affiliated Jiangyin Hospital of Southeast University Medical College and informed consents were signed by the patients or guardians.

Main reagents. EGFR primer was provided by Guangzhou RiboBio Co., Ltd. (Guangzhou, China). Polymerase chain reaction (PCR) primers for BRCA1 and RAP80 were synthesized by Sangon Biotech Co., Ltd. (Shanghai, China). Tissue protein extraction kits were purchased from Nanjing KeyGen Biotech Development Co., Ltd. (Nanjing, China). RNAiso Plus, PrimeScript ${ }^{\circledR}$ RT reagent kit with gDNA Eraser and SYBR ${ }^{\circledR}$ Premix Ex Taq ${ }^{\mathrm{TM}}$ II (Tli RNaseH Plus) were purchased from Takara Biotechnology Co., Ltd. (Dalian, China). TRIzol total RNA extraction kits were from Tiangen Biotech Co., Ltd. (Beijing, China). Reverse transcription-polymerase chain reaction (RT-PCR) kits were from Tiangen Biotech Co., Ltd. Bicinchoninic acid (BCA) protein quantification kits and BeyoECL Plus kits were from Beyotime Institute of Biotechnology (Haimen, China). Rabbit anti-human glyceraldehyde-3-phosphate dehydrogenase (cat. no. 2118; 1:800), BRCA1 (cat. no. 14823; 1:800) and RAP80 (cat. no. 14466; 1:800) monoclonalantibodies, goat anti-rabbit HRP (cat. no. 7074; 1:1,000) and fluorescence secondary polyclonal antibodies (cat. no. 4412; 1:100), all were purchaced from Cell Signaling Technology Europe (B.V., Leiden, The Netherlands).

\section{Experimental methods}

Hematoxylin and eosin $(H \& E)$ histopathological staining. Tissues in control and NSCLC group were dehydrated, embedded in paraffin, and cut into $5 \mu \mathrm{m}$ slices for section making and staining. After $\mathrm{H} \& \mathrm{E}$ staining and sealing, sections in control and NSCLC group were observed under an upright microscope (Olympus, Tokyo, Japan) for pathological differences of tissue sections in the two groups, followed by photography and analysis.

Immunofluorescence staining. The paraffin sections of lung tissues in control and NSCLC group were dewaxed via xylene and dehydrated with gradient alcohol, followed by antigen retrieval. Then sections were washed with $0.01 \mathrm{M}$ phosphate buffered saline (PBS) (pH 7.4) 3 times (5 min each time), sealed in a wet box containing $10 \%$ bull serum albumin at $37^{\circ} \mathrm{C}$ for $30 \mathrm{~min}$. Sections were added dropwise with the fluorescence-labeled antibody appropriately diluted at 1:100, placed in the wet box and incubated at $4^{\circ} \mathrm{C}$ overnight. After being washed with PBS ( $\mathrm{pH} 7.4) 3$ times (5 min each time), sections were added dropwise with the fluorescence-labeled secondary antibody (diluted at 1:100) in the dark, and incubated in a wet box at $37^{\circ} \mathrm{C}$ for another $2 \mathrm{~h}$. Finally,
Table I. RT-PCR primer sequences of BRCA1, RAP80 and $\beta$-actin mRNA.

\begin{tabular}{ll}
\hline Gene name & \multicolumn{1}{c}{ Primer sequence } \\
\hline BRCA1 & F: 5'-ACAGCTGTGTGGTGCTTCT-GTG-3' \\
& R: 3'-CATTGTCCTCTGTCCAGGCATC-5' \\
RAP80 & F:5'-ACATCAAGTCTTCAGAAACAGGAGC-3' \\
& R: 3'-TGCAGCCT GCCTC TTFCCAT-5' \\
$\beta$-actin & F: 5'-GAGCCGGGAAATCGTGCGT-3' \\
& R: 3'-GGAAGGAAGGCTGGAAGATG-5' \\
\hline
\end{tabular}

RT-PCR, reverse transcription-polymerase chain reaction; BRCA1, breast cancer 1; RAP80, receptor-associated protein; mRNA, messanger RNA.

sections were sealed with buffered glycerol, observed and photographed under an upright fluorescence microscope (Bio-Rad Laboratories, Inc., Hercules, CA, USA).

RT-PCR. An appropriate number of lung tissues in control and NSCLC group were rapidly transferred into $1 \mathrm{ml}$ TRIzol reagent, fully ground and homogenized, let stand at room temperature for $5 \mathrm{~min}$ and lysed completely, and centrifuged at $12,000 \mathrm{x} \mathrm{g}$ and $4^{\circ} \mathrm{C}$ for $5 \mathrm{~min}$. Then the supernatant was carefully taken and added with chloroform. The mixture was mixed evenly, let stand at room temperature for $5 \mathrm{~min}$, and centrifuged at $12,000 \mathrm{x}$ g at $4^{\circ} \mathrm{C}$ for $15 \mathrm{~min}$. The supernatant was carefully taken, added with the same volume of isopropanol, let stand at room temperature for $10 \mathrm{~min}$, and centrifuged at $12,000 \mathrm{x} \mathrm{g}$ at $4^{\circ} \mathrm{C}$ for $10 \mathrm{~min}$. The sediment was retained, added with $75 \%$ ethanol and mixed evenly. Finally, RNase-free water was added to completely dissolve the sediment. Then optical density (OD)260/OD280 ratio and the RNA concentration were measured. Stepwise amplification was performed according to the instructions and primer sequence templates shown in Table I, and the reaction products were subjected to RT-PCR analysis.

Western blot analysis. Lung tissues from the control and NSCLC group were washed twice with ice normal saline, respectively. According to instructions of the total protein extraction kit, tissues were added with lysis buffer homogenized using a tissue homogenizer for $1 \mathrm{~min}$ and centrifuged, and the supernatant was collected. The concentration of protein was measured using the BCA protein concentration assay kit. Total protein extracting solution and $2 \mathrm{X}$ loading buffer were mixed evenly at a volume ratio of $1: 1$, treated with boiling water bath for $5 \mathrm{~min}$ and naturally cooled. Sodium dodecyl sulfate polyacrylamide gel electrophoresis (SDS-PAGE) separation gel in an appropriate proportion was prepared according to the molecular weight of target protein, and frozen for about $1 \mathrm{~h}$. Then 5\% SDS-PAGE concentration gel was prepared and frozen for about $30 \mathrm{~min}$. Electrophoretic buffer solution and denatured protein samples were added into the loading wells for loading based on the protein concentration, and the total protein content in each well was kept the same. The electrophoresis was performed under constant pressure 
of $220 \mathrm{~V}$ until the bromophenol blue reached the bottom of the gel. According to the molecular weight of target protein, the gel was cut and placed into transfer buffer. A layer of polyvinylidene fluoride (PVDF) membrane and six layers of filter paper were cut according to the size of the gel. PVDF membrane was immersed into the methanol for $10 \mathrm{sec}$, and PVDF membrane and filter paper were placed into the transfer buffer. Then the positive pole - three layers of filter paper PVDF membrane - gel - three layers of filter paper - negative pole were placed on the membrane transfer instrument in this order. Their edges were aligned to prevent blistering. After the membrane transfer under constant pressure of $110 \mathrm{~V}$ for $2 \mathrm{~h}$, the membrane attached with protein was sealed using $5 \%$ skim milk powder at room temperature for $2 \mathrm{~h}$. The sealed membrane was washed with Tris-buffered saline with Tween-20 (TTBS) for $5 \mathrm{~min}$, and incubated in the primary antibody in corresponding proportion at $4^{\circ} \mathrm{C}$ overnight. After the membrane was washed with TTBS for $5 \mathrm{~min}$ (10 min each time), it was incubated using the corresponding secondary antibody on a shaking table at room temperature for $3 \mathrm{~h}$, and it was washed again with TTBS 3 times $(10 \mathrm{~min}$ each time). After the gel imager was warmed up for $30 \mathrm{~min}$, reagent $\mathrm{A}$ and $\mathrm{B}$ in electrochemiluminescence (ECL) kit were evenly mixed at a volume ratio of 1:1, added dropwise onto the PVDF membrane, followed by color development in the dark for $1 \mathrm{~min}$. Excess liquid around the membrane was sucked dry with the filter paper and the membrane was placed into the gel imager, followed by photography under the dynamic integral mode and observation of results. Image analysis software (V3 Western Workflow ${ }^{\mathrm{TM}}$; Bio-Rad Laboratories, Inc.) was used to analyze the images.

EGFR gene detection. Blood specimens of NSCLC patients were collected to extract gDNA and detect EGFR gene in peripheral leucocytes. Peripheral venous blood was extracted from the participants of the study to extract DNA. EGFR gene was detected via PCR and gel electrophoresis. The forward primer and reverse primer of EGFR gene are as follows: 5'-CT TCGGGGAGCAGCGATGCGAC-3' (forward) and 5'-ACCA ATACCTATTCCGTTACAC-3' (reverse).

Statistical analysis. Experimental data are presented as mean \pm standard deviation (mean \pm SD), and SSPSS 17.0 software (SPSS, Inc., Chicago, IL, USA) was used for the statistical analysis of experimental results. Data were analyzed using analysis of variance or t-test and the post-hoc test was Dunnett's test. $\mathrm{P}<0.05$ was considered to indicate a statistically significant analysis.

\section{Results}

General data of patients. The general conditions of NSCLC patients were recorded, and statistical results are shown in Table II relating to sex, age, history, stage and grade of 51 NSCLC patients.

Smoking status of patients. The smoking status of NSCLC patients was recorded. As shown in Table III, NSCLC patients with a smoking history accounted for $64.71 \%$, those who smoked for more than 20 years accounted for $81.82 \%$, and
Table II. General data of patients.

\begin{tabular}{llr}
\hline Groups & No. & $(\%)$ \\
\hline Sex & & \\
Male & 37 & 72.55 \\
Female & 14 & 27.45 \\
Age & & \\
$<60$ & 30 & 58.82 \\
$\geq 60$ & 21 & 41.18 \\
History & & \\
Adeno & 36 & 70.59 \\
SCC & 15 & 29.41 \\
Stage & & \\
IIIA & 3 & 5.88 \\
IIIB & 12 & 23.53 \\
IV & 36 & 70.59 \\
Grade & & \\
G1 & & 3.92 \\
G1-2 & 2 & 5.88 \\
G2 & 3 & 15.69 \\
G2-3 & 8 & 5.88 \\
G3 & 3 & \\
Unknown & 12 & \\
\hline
\end{tabular}

Table III. Smoking status of patients.

\begin{tabular}{llr}
\hline Groups & No. & $(\%)$ \\
\hline Smoking history & & \\
Yes & 33 & 64.71 \\
No & 18 & 35.29 \\
Smoking pack-year & & \\
$<20$ & 5 & 15.15 \\
$\geq 20$ & 27 & 81.82 \\
Unknown & 1 & 3.03 \\
Quit smoking & & 78.13 \\
Yes & 25 & 3.13 \\
No & 1 & 18.75 \\
Unknown & 6 & \\
\hline
\end{tabular}

those who had quit smoking accounted for $78.13 \%$, suggesting that NSCLC has a certain association with smoking.

$H \& E$ staining results. H\&E staining showed that there were significant pathological differences in lung tissues between control and NSCLC group. Compared with those in control group, the structure of lung tissue was destroyed, nuclear chromatin became darker, and a large number of cancer cells were produced in NSCLC group (Fig. 1).

Immunofluorescence staining results. The expression of BRCA1 and RAP80 in lung tissues in control and NSCLC 

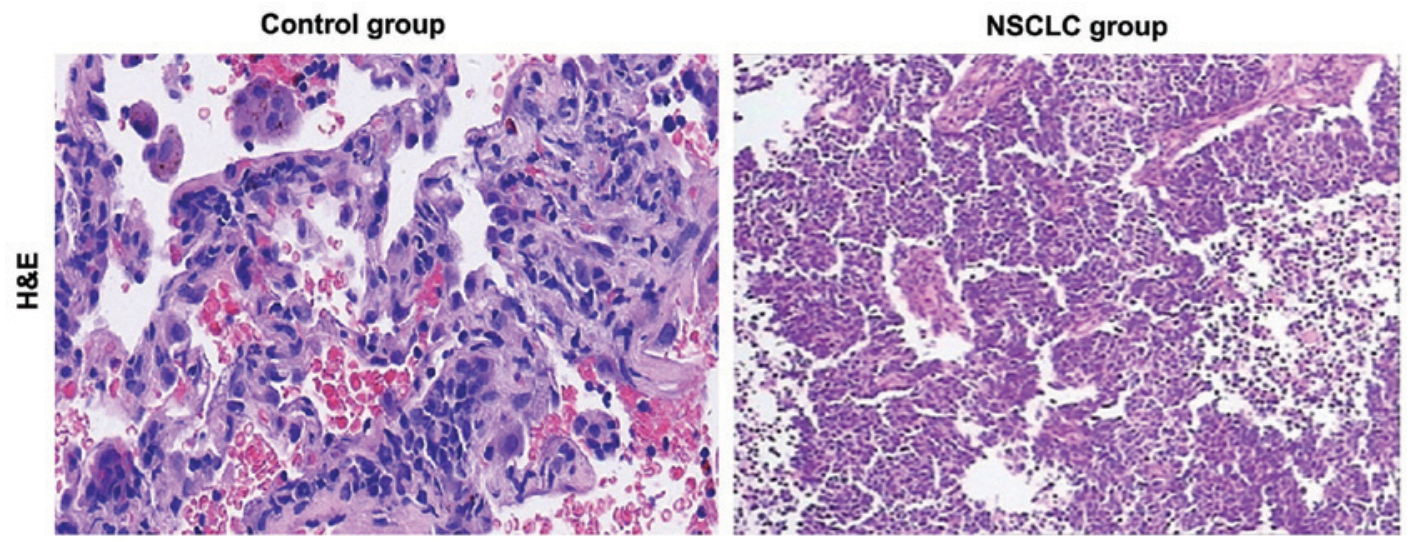

Figure 1. H\&E staining results of lung tissues in control group and NSCLC group (x200). H\&E, hematoxylin and eosin; NSCLC, non-small cell lung cancer.
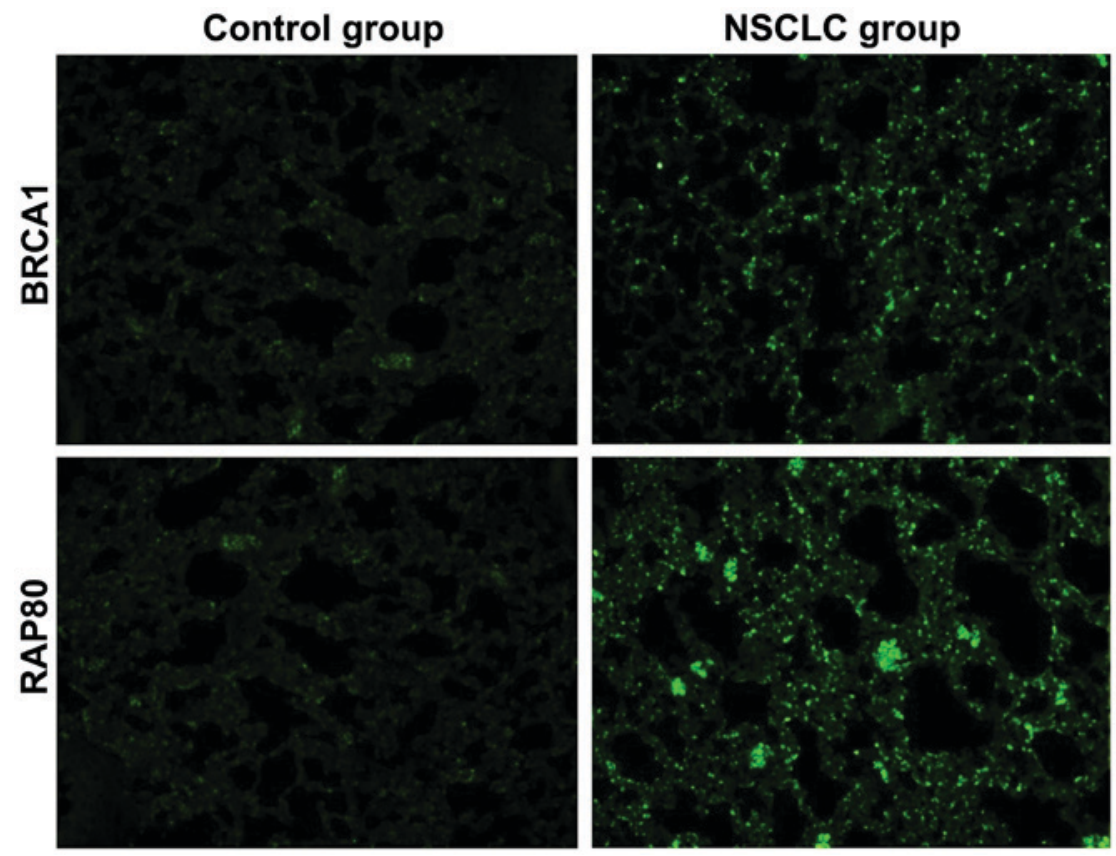

Figure 2. Detection of expression of BRCA1 and RAP80 in lung tissues in control group and NSCLC group via immunofluorescence method (x200). BRCA1, breast cancer 1; RAP80, receptor-associated protein 80; NSCLC, non-small cell lung cancer.

group were detected via immunofluorescence method. Compared with those in control, the expression of BRCA1 and RAP80 in NSCLC group were significantly decreased, indicating that BRCA1 and RAP80 are involved in the occurrence and development of NSCLC (Fig. 2).

$R T-P C R$ results of BRCA1 and RAP8O $\mathrm{mRNA}$. The total RNA was extracted from lung tissue samples in control and NSCLC group, respectively. Results of RT-PCR revealed that BRCA1 and RAP80 mRNA in NSCLC were significantly increased compared with those in control group (Fig. 3).

Western blot results of BRCAI and RAP80 proteins. The protein was extracted from lung tissue samples in control and NSCLC group, respectively. Results of western blot showed that the BRCA1 and RAP80 protein expressions in NSCLC were obviously increased compared with those in control group (Fig. 4).
Table IV. EGFR gene mutations.

\begin{tabular}{lcr}
\hline Type & No. & $(\%)$ \\
\hline Wild-type & 5 & 35.72 \\
Exon 20: s768I; Exon 21: L861Q & 1 & 7.14 \\
L858R & 1 & 7.14 \\
Del19 & 4 & 28.58 \\
Del19, L858R & 1 & 7.14 \\
Exon 20 Q787Q & 1 & 7.14 \\
Exon 21 & 1 & 7.14 \\
\hline
\end{tabular}

EGFR gene mutations. EGFR gene mutations were detected in 14 out of 51 NSCLC patients, including 1 case of Exon20: s768I, 1 case of Exon 21: L861Q, 1 case of L858R, 1 case of DEL19, 1 case of L858R, 1 case of EXON 20 Q787Q, 1 case of EXON 21, 4 cases of DEL19, and 5 cases of wild-type (Table IV). 

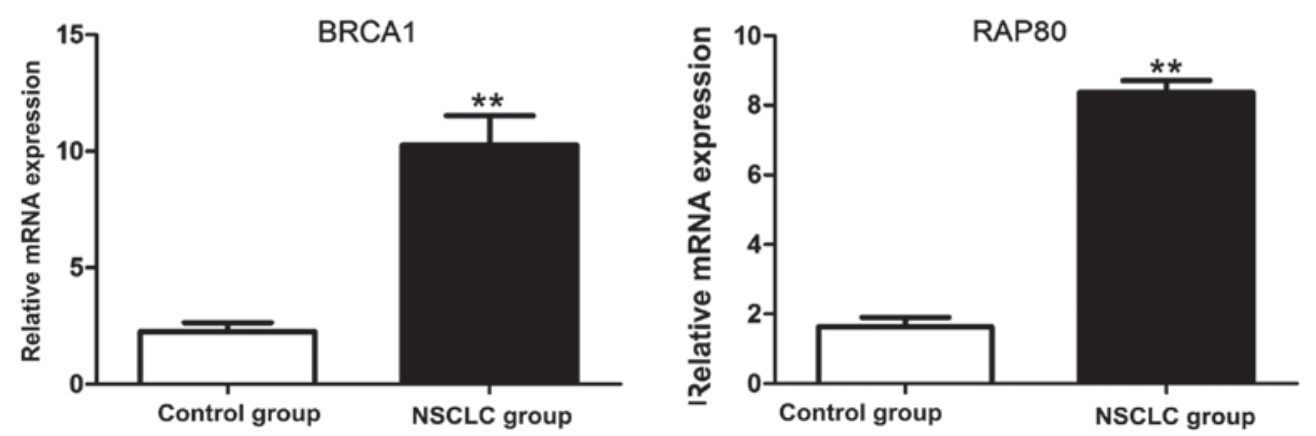

Figure 3. Expression of BRCA1 and RAP80 mRNA in lung tissues in control group and NSCLC group. Compared with control group, ${ }^{* *} \mathrm{P}<0.05$. BRCA1, breast cancer 1; RAP80, receptor-associated protein 80; NSCLC, non-small cell lung cancer.
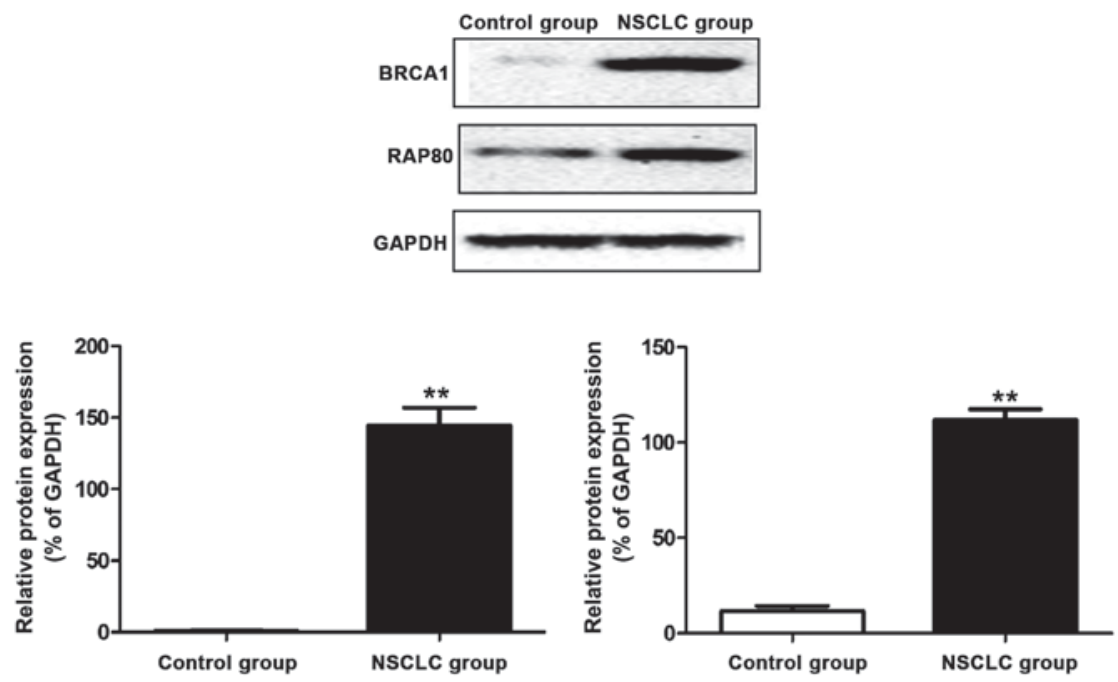

Figure 4. BRCA1 and RAP80 protein expression in lung tissues in control group and NSCLC group. Compared with control group, ${ }^{* *} \mathrm{P}<0.05$. BRCA1, breast cancer 1; RAP80, receptor-associated protein 80; NSCLC, non-small cell lung cancer.

\section{Discussion}

NSCLC, a common malignant tumor, seriously threatens human health (7). According to large data in China, the incidence rate of NSCLC in men ranks first in malignant tumors, while that in women is second only to that of breast cancer (8). With the development of economy and science and technology, the treatment of NSCLC has entered the stage of individualized treatment. In particular, research and development of drugs targeting EGFR, BRCA1 and RAP80 have milestone significance in the diagnosis and treatment of NSCLC (9-11).

EGFR is an expression product of proto-oncogene c-erbB1, a member of the human epidermal receptor family (12). EGFR gene plays an important role in many physiological processes, including cell growth, proliferation and differentiation. Abnormalities in the EGFR gene will lead to a variety of diseases, such as cancer, diabetes mellitus, immunodeficiency and cardiovascular diseases (13). BRCAl is a gene discovered in 1990 , which is directly related to hereditary breast cancer. $B R C A 1$ is a gene that inhibits the occurrence of malignant tumors, which plays an important role in regulating the replication of human cells, genetic material DNA damage repair and normal growth of cells (14-17). Moreover, RAP80 also plays a critical role in DNA damage response, which can promote a series of repair proteins to be located to the correct DNA damage site (18-20). In conclusion, EGFR, BRCAl and RAP80 play key roles in the occurrence and development of tumors, and they may be target genes for tumor treatment.

In the present study, 51 NSCLC patients admitted and treated in the Thoracic Surgery Department of the hospital and who underwent biopsy or surgery from September 2014 to September 2016 were selected, and general data and smoking status were recorded. It was found that NSCLC had a association with smoking. H\&E histopathological staining method was used to detect pathological differences in lung tissues between control and NSCLC group. H\&E histopathological staining showed that the structure of lung tissues was destroyed, nuclear chromatin became darker and a large number of cancer cells were produced in NSCLC compared with those in control group. Immunofluorescent staining method was used to detect the fluorescence expression of BRCA1 and RAP80 proteins in both groups, and results revealed that the expression of fluorescence of BRCA1 and RAP80 proteins in NSCLC group was significantly increased. RT-PCR and western blot proved that the BRCA1 and RAP80 mRNA and protein expression in NSCLC group were significantly increased. Besides, EGFR gene mutations were detected in 14 out of 51 patients. In summary, NSCLC 
has a association with smoking, expression of BRCA1 and RAP80 is closely related to the occurrence and development processes of NSCLC, and EGFR mutation is also significantly associated with NSCLC. It is expected that the key roles of EGFR, BRCA1 and RAP80 in NSCLC in further research will clarify that they can be the targets of prevention, diagnosis and treatment of this disease.

\section{Acknowledgements}

Not applicable.

\section{Funding}

No funding was received.

\section{Availability of data and materials}

The datasets used and/or analyzed during the present study are available from the corresponding author on reasonable request.

\section{Authors' contributions}

XS and FC collected and analyzed general data of patients. XS and HY helped with H\&E histopathological staining. DW performed PCR. NW and MY were responsible for immunofluorescence staining. YF and QW contributed to western blot analysis. All authors read and approved the final manuscript.

\section{Ethics approval and consent to participate}

The study was approved by the Ethics Committee of The Affiliated Jiangyin Hospital of Southeast University Medical College (Wuxi, China) and informed consents were signed by the patients or guardians.

\section{Patient consent for publication}

Not applicable.

\section{Competing interests}

The authors declare that they have no competing interests.

\section{References}

1. Fossella F, Pereira JR, von Pawel J, Pluzanska A, Gorbounova V, Kaukel E, Mattson KV, Ramlau R, Szczesna A, Fidias P, et al: Randomized, multinational, phase III study of docetaxel plus platinum combinations versus vinorelbine plus cisplatin for advanced non-small-cell lung cancer: The TAX 326 study group. J Clin Oncol 21: 3016-3024, 2003.

2. Scagliotti GV, Parikh P, von Pawel J, Biesma B, Vansteenkiste J, Manegold C, Serwatowski P, Gatzemeier U, Digumarti R, Zukin M, et al: Phase III study comparing cisplatin plus gemcitabine with cisplatin plus pemetrexed in chemotherapy-naive patients with advanced-stage non-small-cell lung cancer. J Clin Oncol 26: 3543-3551, 2008 .

3. Cobo M, Isla D, Massuti B, Montes A, Sanchez JM, Provencio M, Viñolas N, Paz-Ares L, Lopez-Vivanco G, Muñoz MA, et al: Customizing cisplatin based on quantitative excision repair cross-complementing $1 \mathrm{mRNA}$ expression: A phase III trial in non-small-cell lung cancer. J Clin Oncol 25: 2747-2754, 2007.
4. Guha U, Chaerkady R, Marimuthu A, Patterson AS, Kashyap MK, Harsha HC, Sato M, Bader JS, Lash AE, Minna JD, et al: Comparisons of tyrosine phosphorylated proteins in cells expressing lung cancer-specific alleles of EGFR and KRAS. Proc Natl Acad Sci USA 105: 14112-14117, 2008.

5. Lynch TJ, Bell DW, Sordella R, Gurubhagavatula S, Okimoto RA, Brannigan BW, Harris PL, Haserlat SM, Supko JG, Haluska FG, et al: Activating mutations in the epidermal growth factor receptor underlying responsiveness of non-small-cell lung cancer to gefitinib. N Engl J Med 350: 2129-2139, 2004.

6. Paez JG, Jänne PA, Lee JC, Tracy S, Greulich H, Gabriel S, Herman P, Kaye FJ, Lindeman N, Boggon TJ, et al: EGFR mutations in lung cancer: Correlation with clinical response to gefitinib therapy. Science 304: 1497-1500, 2004.

7. Pao W, Miller V, Zakowski M, Doherty J, Politi K, Sarkaria I, Singh B, Heelan R, Rusch V, Fulton L, et al: EGF receptor gene mutations are common in lung cancers from 'never smokers' and are associated with sensitivity of tumors to gefitinib and erlotinib. Proc Natl Acad Sci USA 101: 13306-13311, 2004.

8. Sequist LV, Martins RG, Spigel D, Grunberg SM, Spira A, Jänne PA, Joshi VA, McCollum D, Evans TL, Muzikansky A, et al: First-line gefitinib in patients with advanced non-small-cell lung cancer harboring somatic EGFR mutations. J Clin Oncol 26: 2442-2449, 2008.

9. Taron M, Ichinose Y, Rosell R, Mok T, Massuti B, Zamora L, Mate JL, Manegold C, Ono M, Queralt C, et al: Activating mutations in the tyrosine kinase domain of the epidermal growth factor receptor are associated with improved survival in gefitinib-treated chemorefractory lung adenocarcinomas. Clin Cancer Res 11: 5878-5885, 2005

10. Costa DB, Kobayashi S, Tenen DG and Huberman MS: Pooled analysis of the prospective trials of gefitinib monotherapy for EGFR-mutant non-small cell lung cancers. Lung Cancer 58: 95-103, 2007.

11. Marchetti A, Martella C, Felicioni L, Barassi F, Salvatore S, Chella A, Camplese PP, Iarussi T, Mucilli F, Mezzetti A, et al: EGFR mutations in non-small-cell lung cancer: Analysis of a large series of cases and development of a rapid and sensitive method for diagnostic screening with potential implications on pharmacologic treatment. J Clin Oncol 23: 857-865, 2005.

12. Lafarge S, Sylvain V, Ferrara M and Bignon YJ: Inhibition of BRCA1 leads to increased chemoresistance to microtubule-interfering agents, an effect that involves the JNK pathway. Oncogene 20: 6597-6606, 2001.

13. Husain A, He G, Venkatraman ES and Spriggs DR: BRCA1 up-regulation is associated with repair-mediated resistance to cisdiamminedichloroplatinum(II). Cancer Res 58: 1120-1123, 1998.

14. Bhattacharyya A, Ear US, Koller BH, Weichselbaum RR and Bishop DK: The breast cancer susceptibility gene BRCA1 is required for subnuclear assembly of Rad51 and survival following treatment with the DNA cross-linking agent cisplatin. J Biol Chem 275: 23899-23903, 2000.

15. Abbott DW, Thompson ME, Robinson-Benion C, Tomlinson G, Jensen RA and Holt JT: BRCA1 expression restores radiation resistance in BRCA1-defective cancer cells through enhancement of transcription-coupledDNArepair.JBiolChem274: 18808-18812 1999.

16. Mullan PB, Quinn JE, Gilmore PM, McWilliams S, Andrews H, Gervin C, McCabe N, McKenna S, White P, Song YH, et al: BRCA1 and GADD45 mediated G2/M cell cycle arrest in response to antimicrotubule agents. Oncogene 20: 6123-6131, 2001.

17. Quinn JE, Kennedy RD, Mullan PB, Gilmore PM, Carty M, Johnston PG and Harkin DP: BRCA1 functions as a differential modulator of chemotherapy-induced apoptosis. Cancer Res 63: 6221-6228, 2003.

18. Chabalier C, Lamare C, Racca C, Privat M, Valette A and Larminat F: BRCA1 downregulation leads to premature inactivation of spindle checkpoint and confers paclitaxel resistance. Cell Cycle 5: 1001-1007, 2006.

19. Sobhian B, Shao G, Lilli DR, Culhane AC, Moreau LA, Xia B, Livingston DM and Greenberg RA: RAP80 targets BRCA1 to specific ubiquitin structures at DNA damage sites. Science 316: 1198-1202, 2007

20. Kim H, Chen J and Yu X: Ubiquitin-binding protein RAP80 mediates BRCA1-dependent DNA damage response. Science 316: 1202-1205, 2007. International (CC BY-NC-ND 4.0) License. 